Original Research Article

\title{
Adverse drug reactions in hospitalized paediatric patients in a tertiary care center in Kerala, India
}

\author{
Shiva Murthy N. ${ }^{1 *}$, Praveen V. Jose ${ }^{2}$, Basalingappa S. ${ }^{1}$, Safeera K. Ali ${ }^{2}$, Mabel Elizabeth V. K. ${ }^{2}$
}

${ }^{1}$ Department of Pharmacology, ${ }^{2}$ Department of Clinical Pharmacy, DM Wayanad Institute of Medical Sciences, Wayanad, Kerala, India

Received: 26 July 2018 Accepted: 30 August 2018

*Correspondence to: Dr. Shiva Murthy N., Email: shivuindia@gmail.com

Copyright: (C) the author(s), publisher and licensee Medip Academy. This is an openaccess article distributed under the terms of the Creative Commons Attribution NonCommercial License, which permits unrestricted noncommercial use, distribution, and reproduction in any medium, provided the original work is properly cited.

\begin{abstract}
Background: Drug safety information about children is scarcely available. This study aims to describe the ADRs in hospitalized paediatric patients under 12 years of age in paediatrics wards of DM WIMS Hospital, Wayanad, Kerala, a tertiary care center in southern part of India.

Methods: A retrospective study based on data collected as per the ongoing pharmacovigilance program of India (PvPI) was conducted for twelve months period in order to study the ADRs in hospitalized paediatric patients under 12 years of age with at least one medication prescribed. The study was conducted in paediatrics wards of DM WIMS Hospital, Wayanad. WHO-UMC scale and Naranjo's Algorithm was used to evaluate causality, the modified Hartwig and Siegel assessment scale was used to establish severity and the Schumock and Thornton criteria was used to determine preventability.

Results: Forty-two children (42) who experienced 55 ADRs were included in the study. The frequency was higher in children under 1 year of age $(47.62 \%)$. Emergence of ADRs was higher in male patients (59.52\%), in those used three or more medicines together $(71.43 \%)$ and in those with systemic antibiotics $(58.18 \%)$.

Conclusions: Being the first study from Kerala in paediatric patients, it is an important contribution to drug safety profile in children from this region of India. ADRs frequency and other descriptive characteristics are provided for the enrolled children under 12 years of age. ADRs are an additional burden of morbidity and risk, particularly in those who used several medicines, including antibiotics.
\end{abstract}

Keywords: Children, Drug safety, Inpatient, India, Kerala, Pharmacovigilance

\section{INTRODUCTION}

Adverse drug reactions (ADRs) are the major health problems to both the society and as well as for an individual. ADR is defined as a response to a drug which is noxious and unintended, and which occurs at doses normally used in man for prophylaxis, diagnosis or therapy of disease or for the modification of physiological function. ${ }^{1}$

WHO Program for International Drug Monitoring program (WHO-PIDM) was initiated in 1968 for systematic collection of safety information of drugs during their development and in post marketing period. Through this program, pharmacovigilance $(\mathrm{Pv})$ activities are promoted. ${ }^{2}$

WHO promotes pharmacovigilance at country level. Initially 10 countries were inducted as WHO PIDM members. As of January 2016, 123 countries were inducted into WHO PIDM and in addition 28 associate members are awaiting full membership. ${ }^{2}$ India was inducted into this program in 1998. Government of India has started a nationwide Pharmacovigilance Programme of India (PvPI) under the aegis of Central Drugs Standard Control Organization (CDSCO) in the year 2010 having All India Institute of Medical Sciences (AIIMS) as National Coordination Centre (NCC) along with other 22 
regional ADR monitoring centres (AMCs) across the country. As of end of 2017, more than 250 centers were recognized as AMCs. More than 250,787 Individual Case Safety Reports (ICSRs) have been contributed to PvPI through these AMCs. PvPI issued 56 drug safety alerts based on these reports. ${ }^{3,4}$ Authors' institute i.e., DM Wayanad Institute of Medical Sciences (DMWIMS), Wayanad is also an AMC.

India is having large drug consuming population and is the producer of pharmaceuticals in the world with more than 60,000 branded formulations and over 6000 licensed drug manufacturers. ${ }^{3}$ Even though India is one of the top contributors to Vigibase $\AA$ (Vigibase $\AA$ is the database used for management of ADRs under WHO PIDM), the poor post marketing surveillance by pharmaceutical companies is well documented and this adds to the enormity of the problem of ADR reporting. ${ }^{4,5}$ Studies revealed that ADRs are leading to hospitalization ( $0.7 \%$ of total admissions), deaths $(1.8 \%$ of total admissions) and constitute a significant economic burden on patients in India. ${ }^{3}$

Children are not small adults. Pharmacodynamic (PD) and pharmacokinetic (PK) characteristics continuously change until they grow, develop and reach those of adults. ${ }^{6}$ Due to regulatory hurdles in conducting pharmacological research, drug safety and $\mathrm{PK} / \mathrm{PD}$ information is lacking in children. ${ }^{7}$ This is associated with specific problems like under- or over-dosing in some age groups; studies in adult population are not able to demonstrate ADRs related to maturation, growth and development. Due to this, significant proportions of medicines are prescribed on an 'off-label' basis. $^{8}$ In USA, $2-5 \%$ of children are estimated to experience ADRs. ${ }^{9}$ In India, children account for a large part of general population. Therefore, detailed information regarding ADRs is essential to ensure appropriate prescription practices. ${ }^{10}$ Efforts should be made to remind the health care professionals (HCPs) about the importance of paediatric pharmacovigilance.

On extensive literature search, it is understood that no studies are available about ADR profile of children in Kerala. No specific data about ADRs frequency and characteristics has been published for this population. Therefore, this study was planned. The aim of this study was to describe the ADRs in hospitalized paediatric patients under 12 years of age in paediatric wards of DM WIMS hospital, Wayanad, Kerala, a tertiary care center in Southern part of India.

\section{METHODS}

A retrospective, cross-sectional, descriptive study was conducted after institutional ethics committee approval (Ref No. IEC/DMWIMS/July/2018-007). ADRs were collected as per ongoing PvPI program from $1^{\text {st }}$ November 2016 to $30^{\text {th }}$ October 2017 (twelve months period). Confidentiality of data was maintained and only investigators had access to it.
The awareness programs for reporting ADRs by doctors, nurses, medical students and pharmacists (HCPs) were regularly organized in the institute. Paediatric inpatient and intensive care units were provided with proforma published by PvPI (Suspected ADR Reporting (SADR) Form) for voluntary reporting of ADRs by HCPs. ${ }^{11}$ The completed forms were collected by clinical pharmacist. The direct reporting of ADR to the Pv center through telephonic conversation was also encouraged. These ADRs were analysed for inclusion and exclusion criteria by the team consisting of pharmacologists and clinical pharmacists.

\section{Inclusion criteria}

- Inpatients of both sexes

- Aged less than 12 years

- On at least one medication and had developed ADRs formed the subject for the study.

\section{Exclusion criteria}

- ADRs during transfusion of blood or blood products

- Due to drug abuse

- With intentional or accidental poisoning

- Treated on outpatient department.

Patient's details including demographic profile, allergic status, details of drug therapy etc., as per SADR reporting format, were collected. ${ }^{11}$ Onset of the event, dose, frequency, and route of drug administration were also noted.

In addition, causality, severity, preventability and demographic profiles were analyzed. Naranjo's algorithmic scale and WHO-UMC causality categories were used for causality assessment. ${ }^{12,13}$ Modified Hartwig and Siegel Scale and modified Schumock and Thornton Scale were used for assessing severity and preventability respectively. ${ }^{14,15}$

\section{Statistical analysis}

The study used descriptive statistics and the values were expressed in numbers, percentages, mean and standard deviation as appropriate. Data was subdivided based on age, sex, drugs and body systems/organs involved. GraphPad InStat 3 statistical software was used for descriptive statistics. MS Word and MS Excel were used to generate graphs and tables, wherever necessary.

\section{RESULTS}

During the study period 42 paediatric patients were reported to have 55 ADRs. The maximum number of patients had single event i.e. $34(80.95 \%)$ whereas 8 $(19.05 \%)$ cases had multiple ADR events. Out of 42 cases, $25(59.52 \%)$ were male whereas $17(40.48 \%)$ were female (Figure 1). 
The maximum number of cases i.e. 34 (80.95\%) fell between less than 1 year and 5 yrs of age among which 20 $(47.62 \%)$ were from less than 1 year age group (Figure 1). The study group had a mean age of $3.04 \pm 3.23$ years. Antimicrobial agents, drugs affecting central nervous system (CNS) and immune system were responsible for a maximum number of ADRs 47 (85.45\%), followed by the drugs affecting respiratory, cardiovascular (CVS) and gastrointestinal system (GIT) collectively $6(10.91 \%)$ of total ADRs (Figure 2).

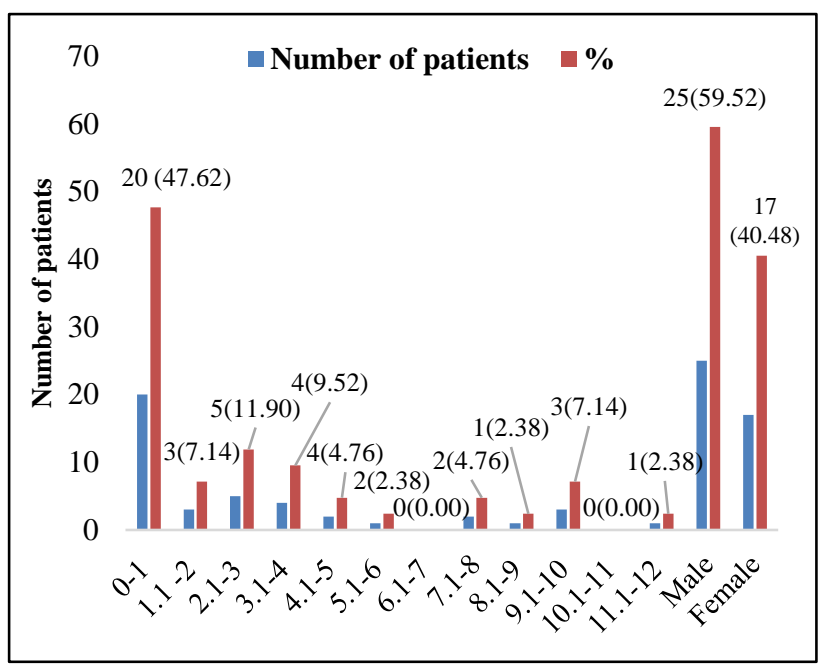

Figure 1: Demographic distribution (age and gender) (n-42(\%)).

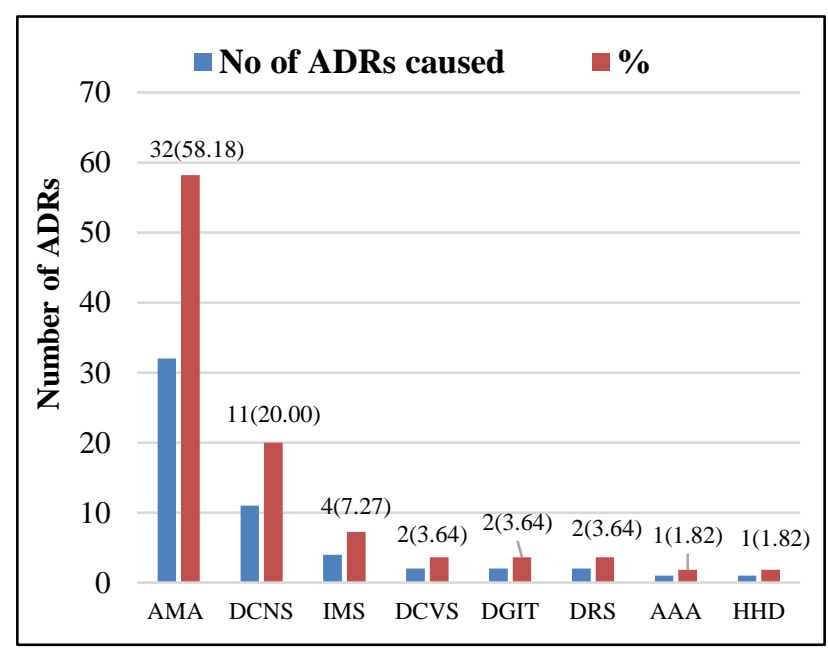

Abbreviations: GIT- gastrointestinal system, CVS- ardiovascular system, CNS-Central nervous system.

Figure 2: Drug systems involved in causing ADRs and their proportions $(\mathrm{n}=\mathbf{5 5}(\%))$.

Fixed dose combination of Amoxicillin + Clavulanic Acid was the leading drug responsible for 19 (34.55\%) of total ADRs followed by Phenobarbitone $6(10.91 \%)$ and Ceftriaxone $5(9.09 \%)$ (Table 1). Twenty-nine (29) of 55 (52.73\%) ADRs affected GIT followed by 14 (25.45\%) affected skin and $5(9.09 \%)$ affected CNS (Table 2).
ADRs related to CVS, endocrine system, blood and coagulation system averaged around $12.73 \%$. Surprisingly, no respiratory ADR was reported. According to WHOUMC causality assessment, most of the ADRs fell in the category of "possible" (56.36\%) followed by "probable" $(34.55 \%)$ and "certain" $(9.09 \%)$ (Table 3$)$.

Table 1: Drugs and their contribution to ADRs.

\begin{tabular}{|c|c|c|}
\hline $\begin{array}{l}\text { Drug suspected } \\
\text { to cause ADR }\end{array}$ & $\begin{array}{l}\text { Total no. of } \\
\text { events } n=\mathbf{5 5} \\
(\%)\end{array}$ & Distribution of ADRs \\
\hline $\begin{array}{l}\text { Amoxicillin } \\
+ \text { Clavulanic } \\
\text { Acid }\end{array}$ & $19(34.55)$ & $\begin{array}{l}\text { Diarrhea (9), Vomiting (4), } \\
\text { Rashes (3), Erythematous } \\
\text { lesion (1), Pruritus (1), } \\
\text { Urticaria (1) }\end{array}$ \\
\hline Phenobarbitone & $6(10.91)$ & $\begin{array}{l}\text { Drowsiness (3), Rashes (1), } \\
\text { Petichiae (1), } \\
\text { Thrombocytopenia (1) }\end{array}$ \\
\hline Ceftriaxone & $5(9.09)$ & $\begin{array}{l}\text { Diarrhea (3), Erythematous } \\
\text { lesion (1), Vomiting (1) }\end{array}$ \\
\hline Prednisolone & $3(5.45)$ & $\begin{array}{l}\text { Diarrhea (1), Erythematous } \\
\text { lesion (1), Vomiting (1) }\end{array}$ \\
\hline Azithromycin & $2(3.64)$ & $\begin{array}{l}\text { Abdominal Pain (1), } \\
\text { Gastritis (1) }\end{array}$ \\
\hline Phenytoin & $2(3.64)$ & Drowsiness (1), Rashes (1) \\
\hline Levitracetam & $2(3.64)$ & $\begin{array}{l}\text { Reduced RBC (1), Reduced } \\
\text { Hemoglobin (1) }\end{array}$ \\
\hline Budesonide & $1(1.82)$ & Oral Candidiasis (1) \\
\hline $\begin{array}{l}\text { Cefixim/ } \\
\text { Metronidazole }\end{array}$ & $1(1.82)$ & Rashes (1) \\
\hline Cefuroxime & & Urticaria (1) \\
\hline Dexomethazone & $1(1.82)$ & Hyperglycemia (1) \\
\hline $\begin{array}{l}\text { Intravenous } \\
\text { Fluid }\end{array}$ & $1(1.82)$ & Discoloration of Body (1) \\
\hline Metronidazole & $1(1.82)$ & Vomiting (1) \\
\hline MMR vaccine & $1(1.82)$ & Febrile Seizure (1) \\
\hline $\begin{array}{l}\text { Ofloxacine / } \\
\text { Clarithromycine }\end{array}$ & $1(1.82)$ & Diarrhea (1) \\
\hline Ondensetron & $1(1.82)$ & Constipation (1) \\
\hline Pantoprazole & $1(1.82)$ & Diarrhea (1) \\
\hline Paracetamol & $1(1.82)$ & Constipation (1) \\
\hline Penicillin & $1(1.82)$ & Diarrhea (1) \\
\hline Propranolol & $1(1.82)$ & Hypotension (1) \\
\hline Salbutamol & $1(1.82)$ & Tachycardia (1) \\
\hline $\begin{array}{l}\text { Spironolactone / } \\
\text { Torasemide }\end{array}$ & $1(1.82)$ & Diarrhea (1) \\
\hline Valproate & $1(1.82)$ & Bleeding (1) \\
\hline
\end{tabular}

Similarly, analysis with Naranjo algorithm-ADR probability scale revealed that majority of the ADRs were "possible" (58.18\%) followed by "probable" (38.18\%) and "definite" (3.64\%) (Table 3).

This may be due to the differences in assessment methods of the scales, the former being subjective and the latter being more objective. Severity assessment using Modified Hartwig and Siegel's scale showed that maximum ADRs were "moderate" $28(50.91 \%)$, followed by "mild" 17 $(30.91 \%)$ and "severe" $10(18.18 \%)$ (Figure 3). 
Using Modified Schumock and Thornton preventability assessment scale $6(10.91 \%)$ ADRs were found to be "definitely preventable" whereas 23 (41.83\%) were "probably preventable" but $26(47.27 \%)$ were "not preventable" (Figure 3).

Table 2: Body systems affected and ADR events reported.

\begin{tabular}{|c|c|c|}
\hline Body system & $\begin{array}{l}\text { Total no. of } \\
\text { events } n=55(\%)\end{array}$ & Distribution of events \\
\hline Gastro Intestinal System & $29(52.73)$ & $\begin{array}{l}\text { Diarrhea (17), vomiting (7), urticaria (2), constipation (2), abdominal } \\
\text { pain (1), gastritis (1), oral candidiasis (1). }\end{array}$ \\
\hline Skin & $14(25.45)$ & $\begin{array}{l}\text { Rashes (5), erythematous lesion (4), discoloration of body (1), } \\
\text { petichiae (1), Purities all over body (1). }\end{array}$ \\
\hline Central Nervous System & $5(9.09)$ & Drowsiness (4), febrile seizure (1) \\
\hline $\begin{array}{l}\text { Blood and Coagulation } \\
\text { System }\end{array}$ & $4(7.27)$ & $\begin{array}{l}\text { Reduced hemoglobin (1), reduced RBC (1), thrombocytopenia (1), } \\
\text { bleeding (1). }\end{array}$ \\
\hline Cardiovascular System & $2(3.64)$ & Hypotension (1), tachycardia (1) \\
\hline Endocrine System & $1(1.82)$ & Hyperglycemia (1) \\
\hline
\end{tabular}

Table 3: Comparison of causality assessment using WHO-UMC scale and Naranjo ADR probability scale.

\begin{tabular}{|llll|}
\hline WHO-UMC scale & \multicolumn{2}{l|}{$\begin{array}{l}\text { Naranjo ADR } \\
\text { probability scale }\end{array}$} \\
\hline $\begin{array}{l}\text { Causality } \\
\text { assessment }\end{array}$ & $\begin{array}{l}\mathbf{n = 5 5} \\
(\mathbf{\%})\end{array}$ & $\begin{array}{l}\text { Causality } \\
\text { assessment }\end{array}$ & $\mathbf{n = 5 5 ( \% )}$ \\
\hline Certain & $5(9.09)$ & Definite & $2(3.64)$ \\
\hline Probable & $\begin{array}{l}19 \\
(34.55)\end{array}$ & Probable & $21(38.18)$ \\
\hline Possible & $\begin{array}{l}31 \\
(56.36)\end{array}$ & Possible & $32(58.18)$ \\
\hline Unlikely & $0(0.00)$ & doubtful & $0(0.00)$ \\
\hline $\begin{array}{l}\text { Conditional/ } \\
\text { Unclassified }\end{array}$ & $0(0.00)$ & - & - \\
\hline $\begin{array}{l}\text { Unassessable/ } \\
\text { Unclassifiable }\end{array}$ & $0(0.00)$ & - & - \\
\hline
\end{tabular}

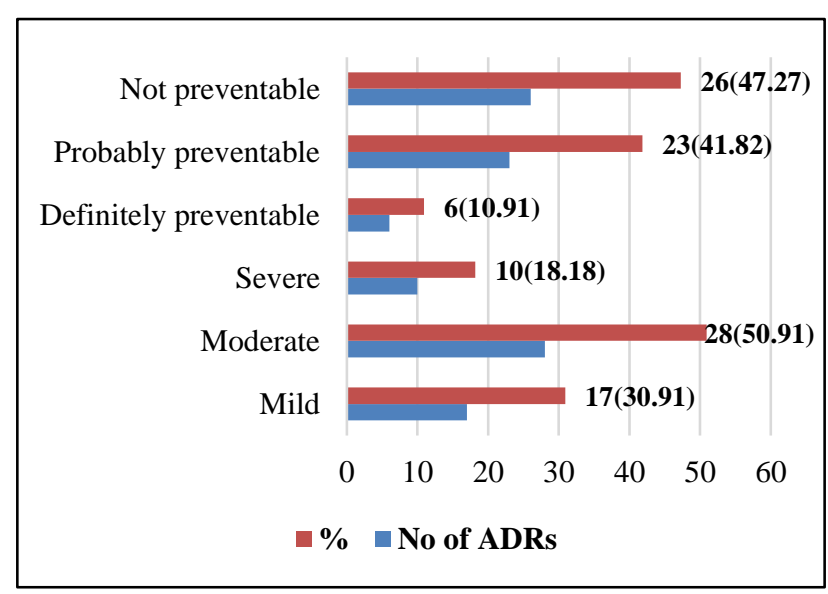

Note: Severity assessment done using modified Hartwig and Siegel's scale and preventability by modified Schumock and Thornton scale.

Figure 3: Severity and Preventability of ADRs [n=55 (\%)].

\section{DISCUSSION}

ADRs have a major impact on already stretched public healthcare system by increasing financial burden on society. It is estimated as 30 billion US\$ annually in the United States of America (USA) alone. Deaths related to ADRs have also been reported. ${ }^{16,17}$ In addition to the human costs, the mean cost of treating an ADR per patient is estimated as 9,491 US\$ with $50 \%$ of this cost being the hospitalization or room charges alone. ${ }^{18}$ In India, the average cost per patient hospitalized with an ADR is around Rs. 4,945 (115 US\$). This cost is considered to be higher as the per capita annual expenditure on health in this country is around 109 US\$. ${ }^{19,20}$

Prescribing of unlicensed and off-label use of drugs, particularly in children, is linked to a higher rate of ADRs compared with the use of licensed medication. In the UK, between $48-57 \%$ of children in hospitals receive an offlabel or unlicensed treatment. It is estimated that 5 out of 8 severe ADRs are linked to off-label use of drugs; immature metabolizing system is the additional risk factor. ${ }^{21,22}$ In present study, a 2.5 year old male child reported with life threatening event. He was diagnosed to have seizures and was treated with phenobarbitone, sodium valproate and levitracetam. Following this, patient reported with reduced hemoglobin, petichiae, bleeding and thrombocytopenia. The causality assessment was found to be of "possible" category. Studies reported that in the age group of newborn to 2 years, ADRs were associated with around 243 deaths each year. ${ }^{23}$ In present study, $54.76 \%$ patients were below 2 years, $80.95 \%$ were below 5 years. Similar age group representation was also reported by other Indian researchers. $^{23-25}$

In present study, authors found that male (59.52\%) children were more often affected by ADRs than female. The WHO ICSR database (VigiBase $\left.{ }^{\circledR}\right)$, also supports this finding. ${ }^{7}$ 
Nevertheless, other studies have shown higher ADRs frequency in female children. ${ }^{23}$

Drug interaction is an added risk in case of polypharmacy and is an important predictor of ADR. ${ }^{1,23,26}$ Physicians are obliged to follow guidelines for managing multiple diseases within the same patient. Generally, these guidelines are devised with single disease in focus. Therefore, they may overlook comorbidities and concomitant medications consumed simultaneously by the patient. Other issues related to polypharmacy are selfmedication, availability of diverse over-the-counter drugs, low literacy in general or low health literacy in particular. Additionally, miscommunication or misunderstanding of physician orders increases the chances of ADRs due to drug-drug interaction and drug-disease interaction. All these pose greater risks to the patient due to prescription cascade and already deteriorating health. ${ }^{27}$ Authors found that $41(97.62 \%)$ cases were prescribed with more than one drug. Thirty (30) $(71.43 \%)$ patients were prescribed with 3 or more drugs. European and non-European countries have also reported similar practices in patients with ADRs. ${ }^{28}$ Exponential rise of ADRs in neonates has been reported when exposed to four or more medications as new-borns and infants are at a higher risk due to immature metabolizing system. ${ }^{22}$ Studies have shown that nonsteroidal anti-inflammatory drug (NSAIDs) exposures are a significant cause of morbidity in children. An autoimmune mechanism of drug reaction to NSAIDs are proposed to cause cross-reactive hypersensitivity between NSAIDs and paracetamol. ${ }^{29}$ Current study supports this as $57.14 \%$ patients received paracetamol as concomitant medication.

Studies estimate that $2.5 \%$ of children who were treated with any drug and $12 \%$ of children who were treated with an antibiotic, experienced a cutaneous ADR. ${ }^{23}$ Present study supports this as antibiotics $(58.18 \%)$ was the major drug group associated with the ADRs and cutaneous $(25.45 \%)$ ADRs was the second common body system affected after GIT $(52.73 \%)$. The antibiotics associated with ADRs include amoxicilline+clavulanic acid, azithromycine, clarithromycine, ceftriaxone, cefixime, cefuroxime, ofloxacine, metronidazole, and penicillin. Recent reports states that, overall, antibiotic clinical trials (CTs) make up less than $1 \%$ of all registered paediatric CTs and results of these studies delayed with average completion time of 2 years. ${ }^{30}$ This lacunae may be supplemented effectively by paediatric Pv studies.

In the present study, 7 of 42 children developed more than one ADRs and remaining patients had just one. Those with more than one event developed adjacent manifestations simultaneously. On thorough evaluation, authors concluded that, adjacent ADRs were an extension of the same reaction.

Diarrohea (17 patients (30.91\%) was the commonest ADR reported in the present study. Followed by vomiting (12.73\%), Rashes (9.09\%), erythematous lesions (7.27\%) and drowsiness $(7.27 \%)$ which were the other common manifestations. GIT $(52.73 \%)$ and skin $(25.45 \%)$ were the most common organs involved. Similar organ system involvement was reported by Reena et al. ${ }^{24}$ In contrast to this, elderly patients reported to suffer from constipation $(16.25 \%)$, vomiting $(7.18 \%)$ and diarrhea $(5.31 \%)$ as the common ADRs. Tramadol and piperacillin + tazobactam were reported to commonly cause GIT symptoms in elderly. ${ }^{31}$ As discussed earlier, some tissues may be more sensitive to specific compounds in early life, irrespective of a given concentration or exposure, whereas others will be less sensitive. This will affect population-specific PD. In fact, the most crucial factor in neonates is their rapidly evolving physiology. ${ }^{32}$ In general, PK and PD are more variable in children than in adults and on an average, children can tolerate larger dosages and have faster clearances of many drugs than adults. The dosages based on body surface area are considered to yield more consistent serum concentrations and therapeutic or toxic effects than dosages based on body weight. ${ }^{33}$ Thus, data generated through PK/PD studies in children may help in providing guidelines for selection of dose and frequency of drugs and minimize the incidence of ADRs.

The causality assessment of ADRs has a pivotal role in drug development and in clinical practice. Generally, any of the following three methods are used for causality assessment; expert judgment (global introspection); probabilistic approach; algorithms method. ${ }^{34,35}$ Based on probabilistic approach, 9.09\% of ADRs were "certain", $34.55 \%$ were "possible" and $56.36 \%$ were "probable". However, on applying algorithms method, $3.64 \%$ were "definite", $38.18 \%$ were "probable" and $58.18 \%$ were "possible" respectively. Kishour et al, reported 90\% ADRs were "probable" and $10 \%$ were "possible". Priyadharsini et al, reported that $80 \%$ ADRs were "probable", $17 \%$ were "possible" and 3\% were "definite".23,25 Present study observations were consistent with the other reports published from India. ${ }^{23,25}$

Majority studies use Schumock and Thornton as the method to assess preventability. ${ }^{1}$ In the present study on applying this method, $6(10.91 \%)$ ADRs were "definitely preventable" whereas $23(41.82 \%)$ were "probably preventable" and $26(47.27 \%)$ were "not preventable". Reena et al, reported 3\% definitely preventable and $77 \%$ probably preventable ADRs. ${ }^{24}$ As per studies, median preventability of ADRs in hospitals has been reported as $35.2 \%(18.7 \%-73.2 \%) .{ }^{36}$ Reports suggests some common preventable reasons as inappropriate indication, inadequate patient education, irrational prescription, lack of prophylaxis for the known ADR, lack of monitoring of intake of drug, inappropriate dose and duration of treatment and treatment protocol not followed. ${ }^{1}$ If suitable measures are built in the standard operating procedures in hospitals, majority of the ADRs may be prevented.

Limitations of the study are outpatient cases, over the counter drug administration and home medication errors were not taken into account and are accepted as a drawback 
of this study because these are also major factors for causing ADRs. Additionally, sample size was not calculated due to difficulties in establishing the general population and an observation period of 12 months was allowed to establish an ADR incidence which resulted in similar findings to those reported in other studies. ${ }^{7,10,23,24}$ In addition, only $3.64 \%$ and $9.09 \%$ of ADRs found were labelled as definite as per algorithm and probabilistic causality assessment criteria respectively. This was due to difficulties associated with case analysis. Other researchers also pointed out disagreements between the different algorithms in assessing causality for the same ADR reports. Disagreements was considerable for three major criteria: timing of event, de-challenge and alternative etiologic cases. ${ }^{34,35}$

\section{CONCLUSION}

To conclude, paediatric patients with risk factors like, male gender, aged less than 3 years, treated with an antimicrobial agent, having polypharmacy and on paracetamol as concomitant medication were more susceptible for ADRs. GIT and cutaneous symptoms were commonly seen in these patients. Being first study from Kerala in paediatric patients, this study is an important contribution to drug safety profile in children from this region. This study establishes the ADRs frequency and other descriptive characteristics on a defined time frame for enrolled children under 12 years of age. Studies similar to authors' study should be conducted and published on regular basis. This is expected to add data to existing database and promote evidence-based decision-making in identifying safety alerts and expected to support measures in strengthening the public healthcare system.

\section{ACKNOWLEDGEMENTS}

Authors would like to thank DMWIMS, Wayanad management and staff of Pharmacology department. Also Mrs. Sowmya Nataraj, Bangalore and Dr. Siddesh. RC Forensic Medicine department for proof reading support.

Funding: No funding sources

Conflict of interest: None declared

Ethical approval: The study was approved by the Institutional Ethics Committee

\section{REFERENCES}

1. Smyth RMD, Gargon E, Kirkham J, Cresswell L, Golder S, Smyth R. Adverse drug reactions in children -a systematic review. PLoS One.2012;7(3):e24061.

2. The WHO Programme for International Drug Monitoring. Available at: http://www.who.int/medicines/areas/quality_safety/sa fety_efficacy/National_PV_Centres_Map/en/.

Accessed on 24 Jul 2018.

3. Kalaiselvan V, Thota P, Singh GN. Pharmacovigilance Programme of India: Recent developments and future perspectives. Ind $\mathbf{J}$ of Pharmacol. 2016;48(6):624-28.

4. Thota P, Thota A, Medhi B, Sidhu S, Kumar P, Selvan VK, Singh GN. Drug safety alerts of pharmacovigilance programme of India: A scope for targeted spontaneous reporting in India. Perspectives Clin Res. 2018 Jan;9(1):51.

5. Anuradha HV, Shivaswamy KN, Rachana PR. Evaluation of cutaneous adverse drug reactions due to antimicrobial agents: a prospective study. IOSR J of Dent and Medi Sci. 2015;4(11):19-22.

6. Baek HJ, Cho YS, Kim KS, Lee J, Kang HR, Suh DI. Multidisciplinary approach to improve spontaneous ADR reporting in the pediatric outpatient setting: a single-institute experience in Korea. Springer Plus. 2016 Dec 1;5(1):1435.

7. Salas RD, Díaz-Agudelo D, Burgos-Flórez FJ, Vaca C, Serrano-Meriño DV. Adverse drug reactions in hospitalized Colombian children. Colombia Med. 2016 Sep;47(3):142-7.

8. Napoleone. Children and ADRs (Adverse Drug Reactions). Italian Journal of Pediatrics. 2010;36:4 Available at: http://www.ijponline.net/content/36/1/4. Accessed on 24 Jul 2018.

9. Lieber NS, Ribeiro E. Adverse drug reactions leading children to the emergency department. Rev Bras Epidemiol. 2012 Jun;15(2):265-74.

10. Divyalasya TVS, Vasundara KHT, Yashoda, Pundarikaksha HP, Kudagi BL, Ramamohan P. Adverse drug reactions in paediatric patients in a tertiary care hospital in India: a prospective observational single centre study. Int $\mathrm{J}$ Basic Clin Pharmacol. 2016 Oct;5(5):2130-37.

11. Suspected Adverse Drug Reaction Reporting Form. Available at:

http://www.cdsco.nic.in/writereaddata/ADR\%20form \%20PvPI.pdf. Accessed on 24 Jul 2018.

12. Naranjo CA, Busto U, Sellers EM, Sandor P, Ruis I, Roberts EA, et al. A method for estimating the probability of adverse drug reactions. Clin Pharmacol Ther.1981;30:239-45.

13. The use of the WHO-UMC system for standardized case causality assessment. Available at: http://www.who.int/medicines/areas/quality_safety/sa fety_efficacy/WHOcausality_assessment.pdf. Accessed on 24 Jul 2018.

14. Hartwig SC, Siegel J, Schneider PJ. Preventability and severity assessment in reporting adverse drug reactions. Am J Health System Pharmacy. 1992 Sep 1;49(9):2229-32.

15. Schumock GT, Thornton JP. Focusing on the preventability of adverse drug reactions. Hospital Pharmacy. 1992 Jun;27(6):538.

16. Kazeem AO, Henry C, Olisamedua FN, Idowu OS, Iyabo $\mathrm{O}$. Incidence and cost estimate of treating pediatric adverse drug reactions in Lagos, Nigeria. Sao Paulo Med J. 2011;129(3):153-64.

17. Gholami K, Parsa S, Shalviri G, Sharifzadeh M, Assasi N. Anti-infectives-induced adverse drug 
reactions in hospitalized patients. Pharmacoepidemiol Drug Safety. 2005 Jul;14(7):501-6.

18. Wu WK, Pantaleo N. Evaluation of outpatient adverse drug reactions leading to hospitalization. Am J Health Syst Pharm. 2003;60(3):253-59.

19. Rajakannan T, Mallayasamy S, Guddattu V, Kamath A, Vilakkthala R, Rao PG, et al. Cost of adverse drug reactions in a South Indian tertiary care teaching hospital. J Clin Pharmacol. 2012 Apr;52(4):559-65.

20. Patel KJ, Kedia MS, Bajpai D, Mehta SS, Kshirsagar NA, Gogtay NJ. Evaluation of the prevalence and economic burden of adverse drug reactions presenting to the medical emergency department of a tertiary referral centre: a prospective study. BMC Clin Pharmacol. 2007 Dec;7(1):8.

21. Hopf YM, Bond C, Francis J, Haughney J, Helms PJ. 'The more you link, the more you risk'-a focus group study exploring views about data linkage for pharmacovigilance. $\mathrm{Br}$ J Clin Pharmacol. 2014 Nov;78(5):1143-50.

22. Kaushal R, Bates DW, Landrigan C, McKenna KJ, Clapp MD, Federico F, Goldmann DA, et al. Medication errors and adverse drug events in pediatric inpatients. JAMA. 2001 Apr 25;285(16):2114-20.

23. Priyadharsini R, Surendiran A, Adithan C, Sreenivasan S, Sahoo FK. A study of adverse drug reactions in pediatric patients. J Pharmacol Pharmacotherapeut. 2011 Oct;2(4):277.

24. Reena V, Jyotsna V, Nitin V, Parag S, Niket R. A study of adverse drug reactions in paediatric age group with assessment of causality, severity and preventabilty in a tertiary care hospital. J Dent Med Sci. 2014;13(5):42-8.

25. Digra KK, Pandita A, Saini GS, Bharti R. Pattern of adverse drug reactions in children attending the department of pediatrics in a tertiary care center: a prospective observational study. Clin Med Insights: Pediatrics. 2015 Jan;9:CMPed-S29493.

26. Impicciatore $\mathrm{P}$, Choonara I, Clarkson A, Provasi D, Pandolfini C, Bonati M. Incidence of adverse drug reactions in paediatric in/out-patients: a systematic review and meta-analysis of prospective studies. Br J Clin Pharmacol. 2001 Jul;52(1):77-83.

27. Mortazavi SS, Shati M, Keshtkar A, Malakouti SK, Bazargan M, Assari S. Defining polypharmacy in the elderly: a systematic review protocol. BMJ Open. 2016 Mar 1;6(3):e010989.

28. Rashed AN, Wong IC, Cranswick N, Tomlin S, Rascher W, Neubert A. Risk factors associated with adverse drug reactions in hospitalised children: international multicentre study. Eur J Clin Pharmacol. 2012 May 1;68(5):801-10.

29. Titchen T, Cranswick N, Beggs S. Adverse drug reactions to nonsteroidal anti-inflammatory drugs, COX-2 inhibitors and paracetamol in a paediatric hospital. Br J Clin Pharmacol. 2005 Jun;59(6):718-23.

30. Thompson G, Barker CI, Folgori L, Bielicki JA, Bradley JS, Lutsar I, et al. Global shortage of neonatal and paediatric antibiotic trials: rapid review. BMJ Open. 2017 Oct 1;7(10):e016293.

31. Shree Lakshmi Devi S, Basalingappa S, Abilash SC. A study of adverse drug reactions among elderly patients in a tertiary care hospital. Int $\mathrm{J}$ Basic Clin Pharmacol. 2017;Aug;6(8):1894-99.

32. Allegaert K, Anker JN. Adverse drug reactions in neonates and infants: a population-tailored approach is needed. Br J Clin Pharmacol. 2015 Oct 1;80(4):78895.

33. Crom WR. Pharmacokinetics in the child. Environ Health Perspect. 1994;102(Suppl 11):111-17.

34. Arimone Y, Miremont-Salamé G, Haramburu F, Molimard M, Moore N, Fourrier-Réglat A, et al. Interexpert agreement of seven criteria in causality assessment of adverse drug reactions. Br J Clin Pharmacol. 2007 Oct 1;64(4):482-8.

35. Belhekar MN, Taur SR, Munshi RP. A study of agreement between the Naranjo algorithm and WHOUMC criteria for causality assessment of adverse drug reactions. Indian J Pharmacol. 2014 Jan;46(1):117.

36. Kanjanarat P, Winterstein AG, Johns TE, Hatton RC, Gonzalez-Rothi R, Segal R. Nature of preventable adverse drug events in hospitals: a literature review. Am J Health Sys Pharma. 2003 Sep 1;60(17):1750-9.

Cite this article as: Murthy SN, Jose PV, Basalingappa S, Ali SK, Elizabeth MVK. Adverse drug reactions in hospitalized paediatric patients in a tertiary care center in Kerala, India. Int J Basic Clin Pharmacol 2018;7:1998-2004. 